\title{
AS ESCOLAS E A AUTONOMIA Conclusões de um estudo de caso
}

\section{Elsa Ribeiro ${ }^{1}$ \\ Joaquim Machado ${ }^{2}$}

Resumo: A governação das escolas em Portugal tem hoje um "regime de autonomia, administração e gestão". Contudo, o peso do Estado centralizador e as poucas alterações entretanto ocorridas na administração das escolas portuguesas, faz da autonomia uma temática muito abordada em sede discursiva, mas com reduzida aplicação na prática.

Revisitamos o percurso que as escolas tiveram de percorrer para contratualizarem a autonomia com a tutela, desde a avaliação externa até à celebração do contrato de autonomia, uma vontade contratualizada.

Procedemos ao estudo empírico, com recurso a uma metodologia de investigação qualitativa, efetuámos um estudo de caso numa escola secundária, situada na zona norte, que celebrou em 2007 um contrato de autonomia, procurando compreender o impacto da governação por contrato na escola e as conceções dos atores educativos sobre autonomia contratualizada.

Palavras-chave: Escola, Centralismo, Autonomia, Contrato.

Abstract: The Portuguese public schools governance has, nowadays, a "regimen of autonomy, administration and management". However, the heavy interference of the centralizing State and the scarce alterations that have been occurring in the administration of the Portuguese public schools has turned the autonomy into a wide dealt subject within academic discussion, in spite of its reduced practical application.

We have revisited the course that the schools had to go through in order to be able to establish a contract of autonomy with the ward, ever since the external evaluation up to the celebration of an autonomy contract. In other words: a "contracted" will.

We have proceeded to the empirical study, resorting to a qualitative inquiry methodology and we have carried out a study case

\footnotetext{
${ }^{1}$ Agrupamento de Escolas Vieira de Araújo - elsaribeiro@ gmail.com

${ }^{2}$ Universidade Católica Portuguesa - jomachado@porto.ucp.pt
} 
in a secondary school, situated in the north of Portugal, that had celebrated in 2007 an autonomy contract, in order to try to understand the impact of the governance per contract in schools and the conceptions of the educational performers on contracted autonomy.

Key words: School, Centralism, Autonomy, Contract.

\section{INTRODUÇÃO}

O sistema educativo português sempre foi muito centralizado, desempenhando o Estado um papel uniformizador de toda a política educativa, pelo que falar em autonomia parece ser uma antítese de toda uma prática centenária que nos caracteriza.

A autonomia das escolas tem de ser contextualizada e analisada tendo em conta os normativos legais e as práticas das escolas e da Administração Central, bem como as suas "variações e significações, em articulação com uma constelação de conceitos que gravitam em seu redor, tais como os de descentralização, desconcentração, projeto educativo, comunidade educativa, territorialização das políticas educativas, contrato de autonomia" (Lima, 2006:6).

$\mathrm{Na}$ Lei de Bases do Sistema Educativo (Lei n. ${ }^{\circ}$ 46/86, de 14 de outubro), a autonomia é pela primeira vez referenciada apenas no âmbito dos estabelecimentos de Ensino Superior, mas nessa Lei há lugar à descentralização, porquanto a conceção de democratização, nela presente, "inclui uma distribuição de poder nas decisões educativas através da descentralização dos órgãos e da participação popular na definição da política e da direção e gestão dos estabelecimentos de ensino" (Fernandes, 1988:507).

O Decreto-Lei n. ${ }^{\circ} 115-\mathrm{A} / 98$, de 4 de maio, considera que "a autonomia das escolas e a descentralização constituem aspetos fundamentais de uma nova organização da educação, com o objetivo de concretizar na vida da escola a democratização, a igualdade de oportunidades e a qualidade do serviço público de educação" (Preâmbulo). Dez anos depois, o DecretoLei n. ${ }^{\circ}$ 75/2008, de 22 de abril pretende reforçar a participação das famílias e comunidades na direção estratégica dos estabelecimentos de ensino e estabelece o órgão unipessoal de topo - o Diretor - a pretexto de favorecimento da constituição de lideranças fortes, visando "reforçar a autonomia e a capacidade de intervenção dos órgãos de direção das escolas para reforçar a eficácia da execução das medidas de política educativa e da prestação do serviço público de educação" (Preâmbulo). Em ambos os diplomas, a Autonomia das Escolas é perspetivada como um meio para assegurar a qualidade do serviço público de educação e abre a possibilidade de celebração de contratos de autonomia. 
Ao abrigo ainda do Decreto-Lei n. ${ }^{\circ}$ 115-A/98, em 10 de setembro de 2007 vinte e duas escolas celebraram com o Ministério da Educação um contrato de autonomia, onde, de acordo com a Portaria $n^{\circ} 1260 / 2007$, de 26 de setembro, se elencam os objetivos gerais e operacionais e os compromissos a cumprir por ambas as partes: "Estes compromissos e deveres mútuos visam melhorar as condições de realização do serviço público de educação confiado às escolas, cujas dimensões abrangem o acesso à escola, o sucesso dos alunos, a formação para a cidadania, os cuidados de apoio e guarda, a organização e o funcionamento da escola, designadamente no que respeita aos processos de participação interna e externa" (Formosinho et al, 2009:2).

A nossa investigação é de natureza qualitativa, visa compreender o processo de contratualização da autonomia em Portugal e consiste no estudo do caso de uma escola secundária, situada no norte do país, com contrato de autonomia a partir daquela data. A Escola está situada numa região historicamente marcada por baixas taxas de escolarização e baixos índices de qualificação escolar, mas com grande crescimento populacional.

Assim, pretendendo compreender como a escola se preparou para celebrar o contrato de autonomia, percorremos o trajeto por ela efetuado desde o processo de Avaliação Externa em 2006 até à celebração do contrato de autonomia em 2007 e apresentamos dados documentais acerca do impacto deste contrato no funcionamento da Escola e no sucesso dos alunos, que recolhemos em documentos institucionais (Projeto Educativo, Projeto Curricular de Escola e Regulamento Interno), documentos da Inspeção-Geral de Educação (Relatório de Avaliação Externa, junho de 2006) e documentos elaborados no âmbito do contrato de autonomia (Plano de Desenvolvimento, Contrato de Autonomia para o Desenvolvimento do Projeto Educativo, $1^{\circ}$ Relatório Anual de Progresso (2007/2008), Parecer sobre o $1^{\text {o }}$ Relatório Anual de Progresso (ano escolar 2007/2008), $2^{\circ}$ Relatório Anual de Progresso (2008/2009) e Parecer sobre o $2^{\circ}$ Relatório Anual de Progresso (ano escolar 2008/2009).

Posteriormente, damos conta das perspetivas dos atores escolares sobre autonomia da escola e o impacto do contrato de autonomia na sua dinâmica interna, recolhidas através de quatro entrevistas semiestruturadas a atores locais (identificados por JA, MF, MA e MJ) que desempenham cargos de gestão de topo e coordenação de estruturas de gestão intermédias.

\section{DA AVALIAÇÃO AO PROJETO E AO CONTRATO}

Na pesquisa documental efetuada, constatamos na Escola práticas de autoavaliação destacadas no relatório de Avaliação Externa (junho de 
2006), que atribui a classificação máxima no domínio da "Capacidade de autorregulação e progresso da Escola" e elenca os seus pontos fortes e pontos fracos. São pontos fortes: a aposta na diversificação das ofertas formativas; o empenho e determinação nas lideranças intermédias e de topo; as rotinas de monitorização dos resultados escolares; o bom clima de relacionamento e cumprimento de regras; o elevado nível de participação dos alunos na vida da Escola; a facilidade de acesso aos recursos por parte dos docentes e alunos; a riqueza dos meios de comunicação à disposição da comunidade escolar; e a excelente imagem na comunidade local. Carecem de melhoria os pontos fracos: a sobrelotação e regime de desdobramento; a dificuldade de coordenação e de articulação do pessoal docente ao nível dos departamentos; a carência de espaços para apoios educativos e outras atividades de enriquecimento curricular; a difícil articulação com as escolas do Ensino Básico de origem dos alunos; a necessidade de melhores respostas para atenuar os efeitos das ausências dos docentes; e as dificuldades resultantes da ausência de outros recursos humanos especializados, nomeadamente para assegurar o funcionamento do Serviço de Psicologia e Orientação (SPO) ou a manutenção do parque informático.

A Escola reuniu as condições exigidas no artigo $3^{\circ}$ da Portaria 1260/2007, de 26 de setembro, para celebrar contrato de autonomia: a adoção por parte da escola de dispositivos e práticas de autoavaliação; a avaliação da escola no âmbito do Programa de Avaliação Externa das Escolas e a aprovação pela Assembleia de Escola e validação pela respetiva DRE de um plano de desenvolvimento da autonomia que vise melhorar o serviço público de educação, potenciar os recursos da unidade de gestão e ultrapassar as suas debilidades, de forma sustentada. São objetivos do projeto de desenvolvimento: o combate ao abandono desqualificado, a promoção do sucesso, o aumento da qualidade do uso dos tempos escolares, a promoção da igualdade de oportunidades e a qualificação dos recursos humanos. É este projeto de desenvolvimento que está na base da celebração do Contrato de Autonomia entre a Escola e o Ministério da Educação para vigorar até ao final do ano letivo 2010/2011.

Ao analisarmos o Contrato de Autonomia constatamos que os objetivos operacionais da Escola são o combate ao abandono desqualificado, a promoção do sucesso escolar, o incremento da qualidade do uso dos tempos escolares, a promoção da igualdade de oportunidades e a qualificação dos recursos humanos. Por seu lado, o Ministério da Educação, assume vários compromissos: 1) calendarizar as intervenções na Escola, em articulação com a Parque Escolar, para melhoramento das infraestruturas e equipamentos da Escola, de modo a 
atenuar a sobrelotação e a criar as condições necessárias para o seu funcionamento em regime normal; 2) criar um Serviço de Psicologia e Orientação (SPO), dotado de um Psicólogo, um Assistente Social e um Animador Sociocultural; 3) conceder, anualmente, à Escola o equivalente a dois horários completos de serviço docente ( 44 horas) para reforço do apoio à equipa de gestão ou para a dinamização de projetos ou, em alternativa, o montante financeiro correspondente à parte não utilizada em vencimentos, para reforço de outros meios destinados aos mesmos fins; 4) permitir a transferência para despesas de capital dos saldos que resultem de ganhos de eficiência na execução das despesas correntes financiadas pelo Orçamento de Estado.

\section{A PROGRESSÃO DA ESCOLA}

Nos relatórios anuais de progresso apresentados nos anos letivos 2007/2008 e 2008/2009, a Escola dá conta do grau de consecução dos objetivos prosseguidos e do cumprimento dos compromissos assumidos.

No que concerne ao combate ao abandono desqualificado, este objetivo foi atingido: o abandono escolar precoce foi de $0 \% \mathrm{em}$ 2007/2008 e em 2008/2009; a saída antecipada era de 4,4\% em $2007 / 2008$ e de $0,7 \%$ em 2008/2009; a saída precoce era de $6,8 \%$ em 2007/2008 e de 6,1\% em 2008/2009; a renovação de matrícula no $10^{\circ}$ ano para alunos retidos era de $123 \%$ em 2007/2008 e de $127 \%$ em 2008/2009, devendo-se a percentagem superior a $100 \%$ ao reingresso de alguns alunos que tinham abandonado a escola; a taxa de abandono dos alunos matriculados no $11^{\circ}$ ano era de $2,8 \%$ em 2007/2008 e de $1,6 \%$ em 2008/2009; a taxa de retenção e desistência era de 12,5\% em 2007/2008 e de $11,4 \%$ em $2008 / 2009$, sendo a média nacional relativa a esta taxa de $22,4 \%$ e de $18 \%$, respetivamente.

No que respeita à promoção do sucesso, a maioria dos objetivos operacionais estabelecidos para esta área de intervenção foram alcançados. A taxa de aprovação no $3^{\circ}$ Ciclo era de 90,4\% em 2007/2008 e de $100 \%$ em 2008/2009, mas a taxa de retenção e desistência no $9^{\circ}$ ano foi de $23,6 \%$, valor muito acima da média nacional que foi de $14,3 \%$. A taxa de aprovação no $10^{\circ}$ ano era $95,3 \%$ em $2007 / 2008$ e de $95,6 \%$ em 2008/2009. A taxa de aprovação no $11^{\circ}$ ano foi de $98,7 \%$ em $2007 / 2008$ e de $97,9 \%$ em 2008/2009. A taxa de aprovação no $12^{\circ}$ ano nos cursos qualificantes foi de 83,5\% em 2007/2008 e de 94,7\% em 2008/2009. Nos exames nacionais, em 2007/2008 a Escola teve média superior à média nacional em cinco disciplinas (Português, Matemática A, História A, Física e Química A e Matemática Aplicada às Ciências Sociais) e inferior à média nacional em três disciplinas (Biologia e Geologia, Economia A e 
Geografia A) e, em 2008/2009, teve média superior à média nacional em apenas quatro disciplinas (Biologia e Geologia, História A, Física e Química A e Matemática Aplicada às Ciências Sociais) e inferior à média nacional em cinco disciplinas (Português, Matemática A, Economia A, Geografia A e Literatura Portuguesa). A paridade de matrículas nos cursos para prosseguimento de estudos e nos cursos qualificantes foi no ano letivo de $2007 / 2008$ de $61 \%$ vs $39 \%$, respetivamente, enquanto no ano letivo $2008 / 2009$ foi de $59 \%$ vs $41 \%$, respetivamente. Por outro lado, a colocação de candidatos na $1^{\text {a }}$ fase de acesso ao ensino superior foi de $91 \%$ em 2007/2008 e em 2008/2009. Já em relação à taxa de empregabilidade para os diplomados dos cursos qualificantes, durante os anos letivos de 2007/2008 e 2008/2009 a escola não dispõe de resultados, devido à dificuldade em monitorizar este indicador.

No que concerne ao incremento da qualidade do uso dos tempos escolares, a maioria dos objetivos operacionais nesta área estão dependentes das infraestruturas (in)existentes. Assim, a taxa de aulas ministradas em todos os anos de escolaridade foi de 99,7\% em 2007/2008 e de $99,2 \%$ em 2008/2009. A taxa de aulas ministradas em todas as disciplinas sujeitas a exame nacional era de $98 \%$ no ano letivo e de 2007/2008, exceto a Português que foi de $92 \%$. No ano letivo 2008/2009 a taxa foi de $96,6 \%$ a $97,9 \%$, com exceção da disciplina de Geometria Descritiva A, cuja taxa foi de $90,6 \%$.

Relativamente à promoção da igualdade de oportunidades podemos constatar que em 2007/2008 a taxa de saída antecipada foi mais reduzida na população de Alunos Apoiados pela Ação Social Escolar (AASE) do que nos restantes alunos (4,0\% vs 4,4\%), enquanto a taxa de saída antecipada foi mais elevada $(5,0 \%$ vs $3,9 \%)$. O abandono no $10^{\circ}$ ano na população AASE foi mais reduzido do que entre os restantes alunos (6,2\% vs 6,8\%), o mesmo cenário ocorreu no $11^{\circ}$ ano de escolaridade (2,6\% vs 2,8\%). Em 2007/2008 a população AASE obteve, geralmente, melhores resultados que a média geral. No que respeita à paridade de ingresso em cursos para progressão de estudos e em cursos qualificantes, em 2007/2008, a população AASE teve um rácio superior aos restantes alunos (55\% vs $45 \%$, em vez de $61 \%$ vs $39 \%$ ). No ano letivo de 2007/2008 a taxa de ingresso ao ensino superior dos AASE foi igual à dos restantes alunos (91\%). Em 2008/2009 a taxa de saída antecipada foi mais reduzida na população AASE que nos restantes alunos $(0,0 \%$ vs $0,7 \%)$, enquanto a taxa de saída antecipada foi mais elevada $(5,0 \%$ vs 3,9\%). O abandono no $10^{\circ}$ ano na população AASE foi mais reduzido do que entre os restantes alunos $(2,7 \%$ vs $6,1 \%)$, o mesmo ocorrendo no $11^{\circ}$ ano de escolaridade (1,5\% vs 1,6\%). Em 2008/2009 a população AASE obteve, no geral, melhores resultados que a média geral. No que concerne à 
paridade de ingresso em cursos para progressão de estudos e em cursos qualificantes, em 2008/2009, população AASE teve um rácio superior aos restantes alunos $(53,5 \%$ vs $46,5 \%$ em vez de $59 \%$ vs $41 \%)$. No ano letivo de 2008/2009 a taxa de ingresso ao ensino superior dos AASE foi ligeiramente superior à dos restantes alunos (91,3\% vs 91\%). Também no que respeita ao rácio de certificação de adultos versus certificação de jovens, em 2007/2008 houve 263 novas certificações para jovens e 152 para adultos, enquanto em 2008/2009 ocorreram 277 novas certificações para jovens e 211 para adultos.

No que concerne à qualificação dos recursos humanos internos, em 2007/2008 a percentagem de docentes com qualificação acrescida a uma licenciatura era de 14,5\% e em 2008/2009 de 12,9\%. Em 2007/2008 registou-se um acréscimo de 12 níveis de ensino entre o pessoal não docente, e em 2008/2009 foram acrescentados 18 níveis de ensino. No ano letivo 2007/2008 houve uma diversificação e complemento das competências humanas existentes, tendo sido contratada uma Psicóloga, enquanto em 2008/2009 foram contratados uma Psicóloga, uma Assistente Social e seis técnicos superiores para o Centro Novas Oportunidades (CNO).

\section{A AÇÃO DO MINISTÉRIO DA EDUCAÇÃO}

O Relatório Anual de Progresso respeitante a 2007/2008 refere que o Ministério da Educação decidiu incluir a Escola na $2^{\mathrm{a}}$ Fase do Programa de Modernização das Escolas Secundárias e que estava a decorrer a reconstituição do SPO, dotando-o dos recursos humanos previstos. Entretanto, a Escola não fez uso da contratação de meios humanos docentes para apoio à equipa de gestão ou para a dinamização de projetos, optando por pedir o equivalente financeiro.

Em 2008/2009 foi antecipado o lançamento das obras na Escola, no âmbito da $2^{\mathrm{a}}$ Fase do Programa de Modernização das Escolas Secundárias e foi autorizada a reconstituição do SPO, por contratação de Escola. À semelhança do ano letivo anterior, a Escola não fez uso da contratação de meios humanos docentes para apoio à equipa de gestão ou para a dinamização de projetos, optando por pedir o equivalente financeiro, tendo assim um reforço orçamental de 19893 Euros. Como aspeto mais negativo foi mencionado o recrutamento de recursos humanos docentes:

No final de agosto de 2009, tal como ocorreu em todas as escolas com contrato de autonomia e TEIP's, foi a Escola informada que deveria recorrer ao mecanismo de contratação de Escola, ao abrigo do DL 35/2007, para suprir a maior parte das necessidades residuais já identificadas nos grupos de docência, para efeitos de colocação de 
docentes pelos serviços centrais do ME. (...) Ao abrir as ofertas nos Grupos de Recrutamento após o concurso nacional, viram-se estas Escolas privadas do concurso dos docentes mais experientes e graduados e, muito particularmente, de muitos daqueles que entretanto nelas haviam colaborado, por terem sido colocados noutras escolas, uma vez que lhe foi vedado o acesso a estas $\left(2^{\circ}\right.$ Relatório Anual de Progresso, 2009:17).

A Escola pretende aprofundar as competências locais de recrutamento direto de docentes, mencionando no $2^{\circ}$ Relatório Anual de Progresso que "deve equacionar-se uma realização antecipada desses processos (sempre prévia ao concurso nacional), bem como a absoluta necessidade de possibilitar a prorrogação dos contratos dos docentes que se mantenham necessários, em todos os casos em que foi imperativo o recurso à contratação de escola, desde que haja vontade de ambas as partes".

\section{PERSPETIVAS DA COMISSÃO DE ACOMPANHAMENTO LOCAL (CAL)}

A CAL realça o cumprimento dos compromissos da Escola e do Ministério da Educação: "O Relatório (...) constitui uma prova do cumprimento das metas estabelecidas, no Contrato de Autonomia. (...) Apraz-nos registar que grande parte delas foi superada, já no $1^{\circ}$ ano de vigência do Contrato de Autonomia" (Parecer da CAL, 2008:1). A CAL refere ainda que a escola está a desenvolver o processo de ensinoaprendizagem visando a promoção do sucesso dos alunos: "A escola encontra-se mobilizada para criar as melhores condições de sucesso escolar para todos os alunos" (Parecer da CAL, 2008:1).

No que concerne ao cumprimento dos compromissos assumidos pelo Ministério da Educação em sede do contrato de autonomia, a CAL "congratula-se também pelo facto do Ministério da Educação ter cumprido uma parte muito substancial dos seus compromissos" (Parecer da CAL, 2008:1).

Outros aspetos evidenciados pela CAL são o combate ao abandono escolar, o sucesso dos alunos beneficiários de Ação Social Escolar e a melhoria do clima escolar:

Os objetivos de combate ao abandono escolar e de garantia de sucesso foram atingidos e até superados (Parecer da CAL, 2009:1).

Registando esta Escola um elevado número de alunos beneficiários da ASE (cerca de 50\%), verifica-se com agrado que estes alunos obtêm resultados um pouco acima dos restantes alunos. Para isso contribuirá um clima escolar sustentado numa ética de trabalho e 
de esforço que se reflete na procura da superação de eventuais dificuldades (Parecer da CAL, 2009:1).

No Parecer relativo ao relatório anual de 2008/2009, a CAL considera que houve melhorias em relação aos indicadores do ano letivo anterior, e reitera o cumprimento das metas estabelecidas pela escola:

O Relatório, que se dá aqui por produzido, constitui uma prova do cumprimento das metas estabelecidas no Contrato de Autonomia e, mais do que isso e conforme se tinha deliberado, uma prova de melhoria em relação aos indicadores do ano anterior (Parecer da CAL, 2009:1).

A CAL menciona também os aspetos que devem ser reformulados e potenciados, fazendo referência às metas a alcançar, aos resultados obtidos nos exames nacionais, ao rácio entre cursos Científicohumanísticos e cursos qualificantes e à empregabilidade dos diplomados dos cursos qualificantes. No que respeita às metas a atingir, a CAL considera que "deverá dar-se, no futuro, mais atenção à qualificação do pessoal interno, sobretudo os docentes da escola" e aconselha a revisão interna das metas a alcançar nos próximos anos, dado os bons resultados já obtidos no $1^{\circ}$ ano de Contrato, "para que se mantenha a ambição que tem galvanizado a escola, de criar as condições para que todos alcancem o sucesso escolar" (Parecer da CAL, 2008:1). No que concerne aos resultados dos alunos nos exames nacionais do $12^{\circ}$ ano, que ficaram abaixo do previsto, "a CAL recomenda o estudo das principais falhas verificadas, dentro de cada disciplina, apoiando o projeto da própria Escola em realizar esta análise", e realça que "seria de prever mecanismos de ajuda aos alunos para a realização dos exames nacionais" (Parecer da CAL, 2009:1). No que respeita à procura dos cursos profissionais, a CAL recomenda que "este indicador seja enriquecido com análise do balanço entre os Cursos Científico - humanísticos - Cursos Profissionais à entrada $(60$ - 40) com balanço à saída, evidenciando a qualidade de ambos os tipos de curso" (Parecer da CAL, 2009:1). No âmbito da empregabilidade, a CAL sugere que se realize uma "análise local de empregabilidade dos diplomados pelos cursos profissionais/ qualificantes, uma vez que este indicador é muito relevante para analisar a qualidade, pertinência e oportunidades dos cursos oferecidos" (Parecer da CAL, 2009:1).

A CAL reforça a pretensão da Escola no que respeita à contratação docente, propondo uma forte alteração do sistema de recrutamento anual de docentes, de modo a permitir à Escola "ter os seus recursos, quer por antecipação do concurso face ao concurso nacional ou por escolha prioritária neste mesmo concurso, quer por prorrogação dos contratos 
anuais agora celebrados, nos casos em que isso interesse a ambas as partes" (Parecer da CAL, 2009:2).

\section{EXPECTATIVAS DOS ATORES ESCOLARES E OBJETIVOS DO CONTRATO}

Os professores tinham muitas expectativas na celebração do contrato de autonomia: a melhoria do serviço público prestado, o valor simbólico da autonomia, a ampliação dos espaços existentes e a construção de espaços específicos (laboratórios, auditório e pavilhão gimnodesportivo), a estruturação e o aumento de valências do SPO, a contratação docente e a possibilidade de gerar poupança.

$\mathrm{O}$ grande anseio dos professores da Escola era a requalificação e diversificação dos espaços existentes na Escola, de modo a minimizar a sobrelotação e a existirem salas específicas para as ciências, um auditório e um pavilhão gimnodesportivo.

$\mathrm{O}$ contrato de autonomia é visto como um instrumento potenciador e legitimador de práticas que facilitem a resolução dos problemas da escola, de "alguns constrangimentos do desenvolvimento do Projeto Educativo da Escola", e assegurem "uma melhor prestação do serviço público de educação" (JA, p.1). E permitia esperar a diminuição da dependência da Escola face ao Ministério da Educação: "Crescer em determinadas áreas e demonstrar a capacidade de resolver com mais flexibilidade e sem termos tanta dependência da administração educativa" (JA, p.1).

Mesmo sabendo que associada à autonomia está a maior responsabilização, os professores, alimentados pelo "querer estar na linha da frente" (MA, p.27), lançaram-se na preparação do contrato, que valorizam como fator de motivação, de prestígio e de distinção da qualidade do trabalho realizado, como potenciação da capacidade de decisão da Escola, de maior envolvimento da comunidade local e de favorecimento do sucesso dos alunos. O então Presidente do Conselho Executivo e atualmente Diretor da Escola promoveu reuniões com os vários agentes educativos - docentes, auxiliares de ação educativa e administrativos, alunos, pais e encarregados de educação e parceiros acerca dos pressupostos e objetivos do contrato de autonomia: "O nosso diretor é (...) muito metódico e isso foi planificado, foi trabalhado, houve discussão, houve alguma reflexão, ele deu mais ou menos as diretrizes e depois houve discussão nos departamentos" (MA, p.27); "Na altura, o presidente do Conselho Executivo fez reuniões connosco, tentámos trabalhar todos para o mesmo fim, fomos todos informados, houve uma discussão, apresentação do projeto e das metas que estavam no contrato" (MJ, p.33). 
Porque a Escola estava sobrelotada, o objetivo mais premente era a ampliação e o apetrechamento dos espaços e a construção de salas específicas, de um pavilhão gimnodesportivo e de um auditório. Em segundo lugar, pretendiam um SPO que deixasse de estar dependente de projetos financiados por entidades externas ao Ministério da Educação (ex. PRODEP), garantisse vinculação da psicóloga para assegurar orientação vocacional e apoio a alunos com necessidades educativas especiais (MJ, p.34) e incluísse uma assistente social e uma animadora sociocultural (MF, p. 17), já que a escola se situa numa região com alunos carenciados e com problemas de aprendizagem e nela havia abandono escolar e saída precoce.

Com o contrato, a escola comprometeu-se - "nós nos impusemos" (MF, p. 16) - a combater o insucesso e o abandono escolar, melhorar a "integração sobretudo daqueles alunos provenientes de famílias com extratos sócio económicos mais baixos" e garantir o seu sucesso educativo (MA, p. 27).

Em suma, os grandes objetivos enumerados pelos nossos entrevistados foram: a melhoria das infraestruturas, a reconstituição e aumento das valências do SPO, a superação das metas contratualizadas, a potenciação da integração e do sucesso dos alunos e a melhoria do serviço público de educação. Já ao nível financeiro, a expectativa centrou-se na possibilidade de gerar poupança, que acresceria ao orçamento do ano seguinte, permitindo à Escola uma estratégia financeira planeada e uma contenção do despesismo. A seleção e contratação de docentes num período antes da contratação nacional e a prorrogação dos contratos com os docentes que já tinham trabalhado na Escola e que tinham tido um bom desempenho foram expectativas também referidas pelos atores locais.

\section{IMPACTO DO CONTRATO NA GESTÃO DA ESCOLA}

O impacto do contrato de autonomia é sobretudo ao nível das instalações da escola, do regime de funcionamento e das respostas pedagógicas que a Escola pode oferecer aos seus alunos, da maior responsabilização e motivação dos docentes e da possibilidade da Escola gerar poupança.

Todos os entrevistados realçam a entrada da Escola no programa da Parque Escolar e a consequente melhoria das infraestruturas como um aspeto basilar para alcançar os objetivos a que a Escola se tinha proposto e para o funcionamento em regime normal em 2010/2011. Consideram, no entanto, que não ocorreram alterações substanciais no que concerne à articulação entre as estruturas de gestão de topo e de gestão intermédia: "A relação da gestão de topo com os coordenadores dos diretores de 
turma não se alterou" (MJ, p. 34). Na verdade, é de salientar que o atual Diretor da Escola era Presidente do Conselho Executivo antes na celebração do contrato de autonomia, o Presidente de Conselho Geral era Presidente da Assembleia de Escola, a Coordenadora de Departamento era Delegada de Grupo, com assento no Conselho Pedagógico e a Coordenadora dos Diretores de Turma do Ensino Secundário Regular era Coordenadora dos Diretores de turma do $3^{\circ}$ Ciclo do Ensino Regular.

Contudo, no que respeita ao impacto no funcionamento e na gestão da escola reconhecem que o contrato "contempla um leque de objetivos e de competências e de compromissos, quer da parte da escola, quer da parte do Ministério da Educação, que à época correspondiam a competências e a recursos que a escola não tinha (JA, p. 3). E reconhecem ganhos financeiros: "nós podemos gerar poupança e essa poupança vai acrescer ao orçamento do ano seguinte. (...) No ano de 2008, tivemos uma poupança na ordem dos setenta mil euros e este ano quase que duplicamos, portanto, isto é um sinal de que a escola está a caminhar bem e isto é fruto do Contrato de Autonomia (MF, p.17).

Realçam ainda a maior responsabilização e motivação dos agentes educativos - "As pessoas gostam de ver e ouvir que o seu trabalho foi conseguido. Nós gostamos de ouvir que o nosso trabalho é um trabalho de excelência" (MA, p. 29) -, principalmente no apoio que dão aos alunos e no cumprimento das aulas previstas para cada disciplina.

De 2007 a 2010, ocorreram mudanças nas políticas educativas, algumas das quais concederam a todas as escolas mais poder de decisão em algumas áreas, nomeadamente na nomeação dos coordenadores de departamento e na contratação de docentes por oferta de escola, retirando às escolas com contrato o caráter de exceção que este lhes outorgara. Contudo, permanecem outras "exceções" que legitimam práticas de gestão administrativa e pedagógica, para as quais era necessário solicitar autorização à DRE: "Fomos através desse instrumento buscar respaldo para as desconformidades que são desconformidades virtuosas, desconformidades que de facto permitiam melhores respostas e respostas mais flexíveis e portanto isto gera um conjunto de dinâmicas positivas que tem efeito nos resultados escolares (JA, pp. 9-10). Por outro lado, permitiu que os atores locais se autorizassem a decidir: "O Contrato de Autonomia levou a que nós assumíssemos as omissões da própria lei como um espaço de autonomia, já o era assim, mas antes havia um receio de fazer sem perguntar" (MF, p. 23).

Com o contrato de autonomia, esta Escola adquiriu competências ao nível da organização da componente letiva e não letiva do serviço docente que lhe permitem flexibilizar mais os horários e assumir decisões internas sem as ver consideradas como "desconformidades" carecidas de 
aprovação da DRE: "em algumas áreas encontramos aí o respaldo para coisas que se faziam um bocado na margem das tais desconformidades de que falava" (JA, p.7). Aliás, consideram um ganho do contrato a flexibilização do horário docente e a colocação no horário dos alunos e dos docentes de um bloco destinado à reposição de aulas e ao reforço das aprendizagens, permitindo, assim, o cumprimento integral dos programas e das aulas previstas: "Tivemos, de facto, uma taxa de cumprimento das atividades letivas que superam claramente aquilo que está estabelecido no contrato de autonomia e, possivelmente, as taxas de outras escolas, tal tem a ver com o modelo de flexibilidade que se introduziu" (MF, p.21).

Dispondo a escola anualmente de 44 tempos letivos para apoio à gestão e dinamização de projetos, não utilizou nos três anos de vigência do contrato de autonomia este crédito horário e pediu a conversão em equivalente financeiro para reforço de outros meios destinados aos mesmos fins: "Por essa via, a escola foi buscar de facto uma capacidade de ter recursos financeiros relevantes que correspondem a mais ou menos $20 \%$ daquilo que era a dotação orçamental normal vinda do Orçamento de Estado (JA, p.6)

Por antítese às potencialidades, os entrevistados referem limitações que subsistiram na Escola, mesmo após a celebração do contrato de autonomia, sendo a maior a seleção e recrutamento dos recursos humanos docentes: "Queríamos mais competências ao nível do recrutamento de pessoal, sobretudo para aproveitar aqueles recursos que considerássemos que tiveram uma apreciação positiva" (MF, p. 23)

Uma das entrevistadas referiu o desempenho dos alunos nos exames nacionais como um aspeto que continua a ser uma limitação da Escola: "O desempenho dos alunos nos exames nacionais, principalmente, na Biologia e Geologia, Física e Química A e na Matemática A. Cumprimos metas de sucesso dos alunos, mas essa parte poderá melhorar ainda" (MJ, pp.34-35)

Já no que concerne à autonomia financeira, que, segundo os entrevistados, muitas escolas anseiam, não é vista por esta escola como prioridade: "Essa é uma área que não está muito no topo da agenda" (JA, p.5).

\section{IMPACTO DO CONTRATO NO SUCESSO ESCOLAR}

Ao analisarmos os relatórios anuais de progresso referentes aos anos letivos de 2007/2008 e 2008/2009 constatamos uma subida nas classificações dos alunos e a superação da maioria das metas que a Escola se tinha proposto alcançar, exceto no que respeita aos exames nacionais de ensino secundário nas disciplinas de Biologia e Geologia, Economia A e Geografia A (em 2008) e nas disciplinas de Português, Matemática A, 
Economia A, Geografia A e Literatura Portuguesa (em 2009), nas quais os resultados obtidos pelos alunos desta escola são inferiores à média nacional. Verificamos também que foram superadas as metas estabelecidas no combate ao abandono escolar desqualificado, o mesmo acontecendo com a taxa de ingresso na $1^{\text {a }}$ fase de candidatura ao ensino superior público.

Os entrevistados não atribuem relação direta de causa-efeito, mas consideram que o contrato de autonomia possibilitou práticas que contribuíram para a melhoria dos resultados dos alunos: "Eu tendo a pensar que há sempre alguns efeitos, porque há uma quantidade de coisas que podemos passar a dispor e que puderam contribuir positivamente para os processos educativos, que será indesmentível que não tiveram um efeito (JA, p.8). Na verdade, o facto da Escola se sentir "premiada" contribuiu para o "aumento da autoestima" da organização. A convicção dos agentes locais de que estão a "fazer bem" contribui para que os docentes tenham "uma preocupação por fazer bem, não se alheando da sua quota-parte de responsabilidade. (...) Numa escola com elevada autoestima, com ferramentas que pudessem melhorar as suas práticas, os resultados são muito positivos, mesmo havendo alguns contratempos" (MF, pp. 20-21).

Por outro lado, o estabelecimento de metas e objetivos claros é considerado pelos entrevistados como uma prática muito importante para alcançar o sucesso: "Assumimos compromissos muito claros, muito quantificados, muito objetivos, mas que não dá para estar a deturpar ou a relativizar e aceitamos isso, nem seria de outra maneira (JA, p.10); "Numa reunião geral que se realiza sempre no início do ano nós estabelecemos sempre metas muito claras do que nós pretendemos fazer naquele ano, e portanto, depois todos os procedimentos vão-se ajustando às metas definidas" (MF, p.20)

A flexibilização dos horários docentes, por um lado, e a inserção no horário dos alunos de um bloco para cumprimento dos programas e reforço das aprendizagens permitiram o cumprimento integral dos programas (MA, p.30) e favoreceram o sucesso escolar, mas houve dificuldades iniciais de implementação: "Tivemos algumas dificuldades de implementar esse modelo mas agora está a funcionar bem, a dificuldade tinha a ver com a falta de espaços, por vezes nem todos os docentes terem disponível esse bloco de reposição e às vezes tendo disponível não o podiam usar por falta de salas" (MF, pp. 21-22). A isto ajudou a "obrigação" contratual de melhorar os resultados: "Nós levamos a peito que tínhamos de apoiar os nossos alunos, que era algo que antes não se fazia, apoiávamos os dos outros; agora, quando apoiamos os nossos, temos maior responsabilidade mas também controlamos muito 
melhor os alunos que vão ao apoio, bem como a sua evolução (MA, p. 30).

De igual modo, foi alcançada a meta de erradicação do abandono escolar precoce e foi superada a meta de diminuição da saída antecipada, havendo, na ótica dos entrevistados, uma contribuição direta do SPO, cuja reestruturação e aumento de valências foi um compromisso cumprido pelo Ministério da Educação: "Foi crucial termos um técnico especializado que perante os primeiros sinais de alguma fragilidade, de abandono ou possibilidade de abandono, vai para o terreno, vai a casa das pessoas, estabelece pontes com outras entidades locais da área da segurança social, e esses abandonos são evitados" (JA, p. 9).

\section{IMPACTO DO CONTRATO NA PARTICIPAÇÃO DA COMUNIDADE}

Os resultados escolares são considerados bons pelos entrevistados e tal repercute-se na forma como a escola é conotada e valorizada pelos pais e encarregados de educação: "Os pais já se aperceberam desse sucesso e por isso não tentam tirar os alunos daqui. Alguns pais dizemnos 'esta escola é boa e queremos trazer os nossos filhos para cá'. (...) A escola tem qualidade, tem bons elementos, tem uma boa taxa de entrada na faculdade. A escola tem uma identidade própria, já é uma escola de referência, pelo menos aqui no distrito (MJ, p. 35).

A Escola estabelece relações diárias com a comunidade e a celebração do contrato de autonomia potenciou a valorização social da escola: "As pessoa continuam a fazer essas referências e valorização, portanto, eu aceito e reconheço que de facto há uma valorização simbólica que acaba por ser gratificante para a comunidade educativa no seu todo" (JA, p.10). O contrato de autonomia tornou-se fator de atração para a escola: "Isto é significativo se pensarmos que no ano passado tivemos o equivalente a quase duas turmas provenientes de fora da área territorial e que este ano esse número foi alargado e, portanto, acho que isso é um sinal muito positivo de confiança que existe na escola (MF, p.22).

Esta atração refletiu-se também no maior envolvimento dos pais: "Julgo que os pais estão a participar mais na escola, não só por causa do Contrato de Autonomia, mas também por causa da sociedade em que vivemos. (...) Os pais têm uma boa imagem da escola e a maioria considera-a um parceiro importante na vida dos seus filhos" (MJ, pp.3536).

Este aspeto é também realçado por Formosinho et al: "O contrato de autonomia é valorizado pelas escolas pelo valor simbólico que comporta e pela imagem social que promove, bem como pela sua adequação como 
instrumento de governação da escola pública" (2006:196). Estes autores alertam para a necessidade de "não confundir as dificuldades emergentes no processo de aprofundamento da autonomia com condições de impossibilidade da autonomia da escola pública portuguesa (2010:196).

\section{A AUTONOMIA COMO FICÇÃO DESEJADA}

As expectativas e o balanço que os atores escolares fazem do contrato tem a ver com o modo como concebem a autonomia da escola. O significado de autonomia para os docentes entrevistados assenta num maior reforço de competências e de responsabilização, sublinhando as "particularidades" e as "contrapartidas" e relevando "um dar e receber, muito mais evidente numa escola com Contrato de Autonomia, que não era tão visível nas outras escolas" (MF, p. 24). Os nossos entrevistados atribuíram à autonomia da escola o significado de identidade própria, de compromisso recíproco, de aumento da responsabilidade dos agentes educativos, de potenciação do conhecimento da Escola, assim como de cumprimento de metas contratualizadas.

Verificamos que a Escola tinha como principais objetivos a requalificação e diversificação dos espaços existentes, a reestruturação do SPO, e a seleção e recrutamento de docentes, de modo a aumentar o sucesso dos seus discentes e a promover uma melhoria do serviço público prestado. Passados três anos letivos da celebração do contrato de autonomia, a escola integrou a $2^{a}$ fase do programa de modernização da Parque Escolar, vendo as suas infraestruturas melhoradas e ampliadas em 2010, o SPO foi reestruturado e ampliado contando com serviços de psicologia, assistência social e animação sociocultural. Ao nível da seleção e recrutamento dos docentes, a Escola não tem o sistema que deseja, impedindo-a de recrutar antecipadamente os docentes pretendidos.

Face a todos os normativos existentes, poder-se-ia pensar que a autonomia é uma realidade no sistema educativo português, contudo a maioria das escolas encontra-se, segundo Lima (2006:39), no grau zero de autonomia contratualizada "congruente com uma política e administração do tipo centralizado-desconcentrado". Mas a escola onde desenvolvemos o estudo "foi a jogo" (Formosinho et al, 2010:10) e obteve dividendos sem precisar de fazer mais do que já fazia. A escola contratualizou metas que conseguia superar e, deste modo, obteve contrapartidas por parte do Ministério da Educação, "foi buscar mais", sem ter que alterar substancialmente as suas práticas (Azevedo, in Formosinho et al, 2010:10).

Por outro lado, a Escola depara-se frequentemente com a interferência da Administração, recebendo frequentemente, tal como as demais, 
orientações que são para cumprir e relegam a autonomia da escola para a operacionalização local da decisão superior. Esta "interferência" no plano da regulamentação do modus operandi de todas as escolas é percebida pelas escolas como "obstaculizando a diversidade de operacionalização das políticas, desincentivando a possibilidade de normas e regras específicas, potenciando a homogeneização das práticas gestionárias, promovendo a indiferenciação das escolas, convidando as escolas a uma autonomia funcional e até "esvazia(n)do de algum sentido" o contrato de autonomia (Formosinho et al, 2009:13).

A autonomia é imposta pela tutela às escolas, numa política do topo para a base, determinada a nível central, em que são transferidas para as escolas competências que não foram solicitadas. Tal provoca uma resistência dos atores locais à implementação da autonomia das escolas.

Assim, a autonomia continua a ser uma ficção, situando-se mais no plano retórico do que no plano prático, sendo frequente nos discursos políticos. Barroso (2004:49) refere que a autonomia é uma "ficção necessária" num regime democrático e, nessa "ficção necessária", enquadram-se as políticas de governação por contrato. De igual modo, contribuindo a retórica da autonomia para a minimização dos conflitos nas escolas e na relação destas com a tutela a "hipocrisia" (Brunsson, 2006), pode ser uma interessante grelha de análise da ação das partes contratantes.

Contudo, a autonomia continua a ser almejada, continua a ser a "terra prometida" e as escolas querem estar na "linha da frente". A Escola em que desenvolvemos o nosso estudo tinha, desde 2006, práticas de autoavaliação e de autorregulação. Estas práticas foram importantes para que tivesse um bom conhecimento de si e dos seus problemas, que lhe permitiram equacionar prioridades e hierarquizar as pretensões daquilo que era mais necessário. Para as escolas entrarem no processo de celebração do contrato de autonomia era condição necessária que elas tivessem práticas efetivas de autoavaliação e se tivessem submetido à avaliação externa. Assim, o contrato de autonomia é um processo que requer também iniciativa da escola. 


\section{REFERÊNCIAS BIBLIOGRÁFICAS}

BARROSO, João, et al (2006). A autonomia das escolas. Textos da conferência internacional "A autonomia das escolas". Lisboa: Fundação Calouste Gulbenkian.

BRUNSSON, Nills (2006). A organização da hipocrisia - Os grupos em acção: dialogar, decidir e agir. Porto. Edições Asa.

FORMOSINHO, João; FERNANDES, António S. \& MACHADO, Joaquim (2005). Administração da educação - Lógicas burocráticas e lógicas de mediação. Porto: Edições ASA - Colecção em Foco.

FORMOSINHO, João; FERNANDES, António S. \& MACHADO, Joaquim (2007). Contratos de autonomia para o desenvolvimento das escolas portuguesas. Braga: Universidade do Minho (policopiado).

FORMOSINHO, João; FERNANDES, António S.; FERREIRA, Henrique; MACHADO, Joaquim; VERDASCA, José \& MOREIRA, Margarida E. (2009). Um ano de governação por contrato. Relatórios anuais de progresso. Braga: Universidade do Minho (policopiado).

FORMOSINHO, João; FERNANDES, António S., MACHADO, Joaquim \& FERREIRA, Henrique (2010). Autonomia da escola pública em Portugal. Fundação Miguel Leão.

LIMA, Licínio C. (2006). Administração da educação e autonomia das escolas. In LIMA, L. et al, A Educação em Portugal (1986-2006): alguns contributos de investigação. Porto: Sociedade Portuguesa de Ciências da Educação 